\title{
Sociodemographic Characteristics and Prevalence of Self Ear Cleaning in Sokoto Metropolis
}

\author{
Stanley B. Amutta ${ }^{1 *}$, Mufutau A. Yunusa ${ }^{2}$, Kufre R. Iseh ${ }^{1}$, Ayodele Obembe ${ }^{2}$, Enokela Egili ${ }^{3}$, \\ Daniel Aliyu ${ }^{1}$, Mohammed Abdullahi ${ }^{1}$ \\ ${ }^{1}$ ENT Department, Usmanu Danfodiyo University Teaching Hospital, Sokoto, Nigeria \\ ${ }^{2}$ Psychiatry Department, Usmanu Danfodiyo University Teaching Hospital, Sokoto, Nigeria \\ ${ }^{3}$ Family Medicine Department, Usmanu Danfodiyo University Teaching Hospital, Sokoto, Nigeria \\ Email: *samutta14@gmail.com
}

Received September 6, 2013; revised October 5, 2013; accepted November 2, 2013

Copyright (c) 2013 Stanley B. Amutta et al. This is an open access article distributed under the Creative Commons Attribution License, which permits unrestricted use, distribution, and reproduction in any medium, provided the original work is properly cited.

\begin{abstract}
Background: Self ear cleaning with cotton buds and other objects is a common practice. Objective: To determine the sociodemographic characteristics and the prevalence of self ear cleaning habit among patients attending a family medicine clinic in a teaching hospital in Sokoto metropolis. Materials and Methods: This was a 4 weeks prospective study carried out between May and June, 2013 at Usmanu Danfodiyo University Teaching Hospital and Specialist Hospital Sokoto. A structured self response questionnaire containing items on sociodemographic characteristics, frequency of administering objects into the ear and complications of self ear cleaning was administered to the respondents after institutional research ethical clearance. The data were analysed using SPSS for windows version 16.0. P-value was considered significantly if less than 0.05 . Results: A total of 200 subjects were included in this study, comprising of 93 (46.5\%) males and 107 (53.5\%) females. Their ages ranged from 18 - 57 years with the mean age being 30.29 years $( \pm 8.70)$. Eighty percent $(160)$ of the respondents practise self ear cleaning. Types of objects included writing objects and cotton buds. For many of the subjects, the frequency of insertion was once daily and both ears were frequently cleaned. Complications that have arisen due to the practice included otitis externa. Conclusion: Self ear cleaning was prevalent in the subjects. Considering the complications that may arise, ear cleaning is better done by trained health personnel.
\end{abstract}

Keywords: Ear; Cleaning; Self; Wax; Cotton Bud; Sokoto

\section{Introduction}

The habit of cleaning the external auditory canal (EAC) with cotton buds and other objects is a common practice $[1,2]$. Generally, it is done to clean ear wax considered as dirt from the EAC [1,2]. However, this wax resulted from combined secretions of the ceruminous and sebaceous glands and desquamated epithelium from the tympanic membrane and skin lining the external auditory canal form the ear wax [1,3-7].

Accumulation of ear wax in the EAC is the most common and routine otologic problem [4]. Ear wax accumulation obstructed the clinician from viewing the tympanic membrane, caused ear discomfort, otalgia, hearing loss, itching, tinnitus and increased infection risk [4-6]. Rarely, unproductive cough may be the only clini-

\footnotetext{
${ }^{*}$ Corresponding author.
}

cal presentation of impacted ear wax [8]. Some people make a routine attempt to remove the ear wax using cotton bud, and loose tip cotton swabs, feathers, stick and a variety of other objects $[1,2,4,9]$. This act interferes with the self cleansing function of the EAC and the wax which is further pushed medially towards the tympanic membrane [2,4]. Moreover, ear wax habitual removal is a risk factor for repeated trauma, inflammation and weakens the EAC local defence against bacterial and fungal infection $[1,2,9]$.

Previous studies have reported the habit of ear cleaning, objects used to clean the ears, and how frequent and associated with complications [1,2,9]. In Sokoto, NorthWestern Nigeria there is no study conducted on self ear cleaning habit. The purpose of this study was to determine the sociodemographic characteristics of patients who practice self ear cleaning habit and associated with 
complications in Sokoto metropolis, North-Western Nigeria.

\section{Materials and Methods}

This was a prospective study which was carried out over a 4 weeks period between May and June, 2013 at Usmanu Danfodiyo University Teaching Hospital (UDUTH) and Specialist Hospital Sokoto. Usmanu Danfodiyo University Teaching Hospital and Specialist Hospital are tertiary and secondary health institutions respectively. These two institutions are located within Sokoto metropolis. The subjects comprised of both patients and healthy adults (staff and students) of these institutions. However for subjects to be included into this study, should not have ear problems or complaints, give consent to participate in this study and should not be less than 18 years. Exclusion criteria were individuals less than 18 years of age, having ear problems/complaints and not giving consent.

A structured self response questionnaire was administered to the respondents after institutional research ethical clearance was obtained for the study and informed consent. A sample of loose tip cotton bud was shown to the respondents during the response to the questionnaire [2], and they were asked if they will replace the tight cotton bud available in the market with the loose tip cotton bud. Inclusion criteria were being adult and having given consent to participate in the study.

The data obtained was analyzed using SPSS for windows version 16.0. P-value was considered significant if it was less than 0.05 .

\section{Results}

A total of 200 subjects participated in this study. The mean age of the respondents was 30.29 years $( \pm 8.70$ years). Ninety three (46.5\%) were males and 107 (53.5\%) were female, the ratio being 1:1.2.

From Table 1, the respondents were mostly young people with those in the 21 - 30 years age group comprising more than half of them (58.5\%). One hundred and thirty nine subjects were Muslims while 61 were Christians and more than $60 \%$ of them received tertiary education. Majority of them were civil servants (42.0\%) and students (42.5\%) while Hausa/Fulani ethnic group constituted were 114 (57.0\%).

In Table 2, one hundred and sixty (80\%) of the respondents practise self ear cleaning while 39 (19.5\%) do not clean their ears. The frequency of cleaning per day in the subjects were as follows: those who cleaned once daily were 77 (48.1\%), twice 25 (15.6\%), thrice 7 (4.4\%), four times $1(0.6 \%)$, five times $2(1.3 \%)$ and more than five times 48 (30\%). Cotton bud was the most common object used by the subjects to clean their ears with 146
Table 1. The age distribution of the subjects.

\begin{tabular}{cc}
\hline Age range & Number (\%) \\
\hline $18-20$ & $16(8.0)$ \\
$21-30$ & $117(58.5)$ \\
$31-40$ & $42(21.0)$ \\
$41-50$ & $17(8.5)$ \\
$51-60$ & $8(4.0)$ \\
Total & $200(100.0)$ \\
Gender & \\
Male & $93(46.5)$ \\
Female & $107(53.5)$ \\
Religion & $139(69.5)$ \\
Islam & $61(30.5)$ \\
Christianity & \\
Education & $15(7.5)$ \\
Primary & $33(16.5)$ \\
Secondary & $124(62.0)$ \\
Tertiary & $28(14.0)$ \\
Postgraduate & $13(6.5)$ \\
Occupation & $85(42.5)$ \\
Civil service & $7(42.0)$ \\
Housewife & $1(0.5)$ \\
Missionary & \\
Self employed & \\
Student & \\
Teacher & \\
\hline & \\
\hline
\end{tabular}

(91.2\%), followed by biro cover/tip 6 (3.7\%) and other objects were $8(5.0 \%)$ comprising feather $3(1.9 \%)$, broom stick 2 (1.3\%), finger $2(1.3 \%)$ and match stick 1 $(0.6 \%)$. Removal of dirt 65 (40.6\%) was the most common reason for self ear cleaning among the subjects, followed by itchy ears 48 (30\%), ear wax 25 (15.6\%). The other reasons included ear blockage 22 (13.8\%), water in the ear 10 (6.2\%) and prevention of infection 6 (3.8\%). Both ears were most common frequently cleaned among the subjects with 89 (55.6\%), right ear 47 (29.4\%) and left ear 24 (15\%). Only 13 (8.1\%) respondents accepted to replace the cotton bud with a loose tip cotton bud.

Forty (25\%) of the 160 respondents involved in the self ear cleaning had some complications while 120 (75\%) had no complications. The most common complication was otitis externa $17(10.6 \%)$, followed by retained object in the EAC 11 (6.9\%), pain 10 (6.3\%) and bleeding from EAC 2 (1.2\%).

\section{Discussion}

This prospective cross sectional study was aimed to determine the sociodemographic characteristics, the preva- 
Table 2. Self ear cleaning among the subjects.

\begin{tabular}{|c|c|}
\hline Self ear cleaning & \\
\hline Yes & $160(80.0)$ \\
\hline No & 39 (19.5) \\
\hline \multicolumn{2}{|l|}{ Frequency per day } \\
\hline 1 & $77(48.1)$ \\
\hline 2 & 25 (15.6) \\
\hline 3 & $7(4.4)$ \\
\hline 4 & $1(0.6)$ \\
\hline 5 & $2(1.3)$ \\
\hline$>5$ & $48(30)$ \\
\hline \multicolumn{2}{|l|}{ Objects used } \\
\hline Cotton bud & $146(91.2)$ \\
\hline Biro cover/tip & $6(3.8)$ \\
\hline Other objects & $8(5)$ \\
\hline \multicolumn{2}{|c|}{ Reason for using objects into the ear } \\
\hline Dirt & $65(40.6)$ \\
\hline Itchy ears & $48(30)$ \\
\hline Wax & $25(15.6)$ \\
\hline Other reasons & $22(13.8)$ \\
\hline \multicolumn{2}{|l|}{ Ear frequently clean } \\
\hline Both & $89(55.6)$ \\
\hline Right & $47(29.4)$ \\
\hline Left & $24(15)$ \\
\hline \multicolumn{2}{|l|}{ Complications } \\
\hline Nil & $120(75)$ \\
\hline Otitis externa & 17 (10.6) \\
\hline Lodge object in the EAC & $11(6.9)$ \\
\hline Pain & $10(6.3)$ \\
\hline Other complications & $2(1.2)$ \\
\hline
\end{tabular}

lence of practising self ear cleaning and previous history of complications from the habit. Of the subjects $80 \%$ of them indulged in self ear cleaning. In addition, majority cleaned their ears once daily and both ears were frequently cleaned. Cotton bud was the preferred object for cleaning the ears among the subjects and the most common complication encountered was otitis externa.

Self ear cleaning is a common practice. It is usually done by most people to remove ear wax, which most individual considered as dirt [1,2]. The prevalence of self ear cleaning among the respondents in this study was comparable to previous study in Kaduna, Nigeria [1].

The objects used by the respondents in this study for self ear cleaning varied. The most common object used was cotton bud in $91.2 \%$ of the respondents involved in the habit. This is in agreement with numerous studies $[1,2,5,9]$. Feathers, biro cover/tips, broom stick, match sticks and finger were used by few members of the sub- jects. An unprofessional attempt to clean the EAC is a potential risk factor for ear trauma and otitis externa $[1-5,9]$. Moreover, the risk is greater if done without direct visualization of the EAC, and using wrong instruments or objects not design for removing ear wax or foreign body from the ear.

The majority of the subjects in this study clean their ears 1 - 5 times daily. The breakdown of the frequency of cleaning revealed $48.1 \%$ routinely clean their ears once daily, while $21.9 \%$ clean 2 - 5 times every day and 30\% clean more than five times per day. The rate of cleaning in this study is similar to other report [1,2]. The complication of self ear cleaning among the subjects in this study was $25 \%$. In contrast, Lee, et al. [2] reported from $2 \%$ in Malaysia. The larger sample size in this study may be the possible explanation for this difference. The most common complication encountered in this study was otitis externa, followed by retained object in the EAC, pain and bleeding from EAC and ear wax impaction. Similar complications were reported in other studies [1-5,9,10].

In this study, the most common reason for self ear cleaning was removal of dirt, followed by itchy ears and ear wax. Itchy ears were the most common reason reported by Afolabi et al. [1], while ear wax was the predominant reason in the study by Lee et al. [2]. Majority of the respondents in this study considered ear wax as dirt. Ear wax is not dirt, but natural product of the EAC that prevents infection and foreign bodies from easily entering the EAC [1-5]. Cleaning the EAC with cotton bud and other objects is a behavioural factor that contributes to impacted ear wax because the action opposes the self cleansing property of the EAC, mechanical trauma to the EAC wall, tympanic membrane perforation and secondary infection [3-5,9]. The appropriate indications for ear wax removal include symptomatic ear wax impaction and to view the tympanic membrane during ear examination $[3,4]$. Furthermore, the ear wax removal should be done by trained and skilled ENT Nurses, General Physicians and Otolaryngologists.

Itchy ears require complete evaluation by an otolaryngologist because fungal infection of the external ears and allergic conditions such as allergic dermatitis and allergic rhinosinusitis may be responsible. Self ear cleaning because of blockage as practiced by $6.2 \%$ of the respondents in this study is dangerous due to the risks mentioned above. Moreover, middle ear lesion that leads to fluid accumulation in the middle ear such as otitis media with effusion (OME) presents with sensation of ear blockage and hearing impairment.

Ironically, 3.8\% of the respondents indulged in self ear cleaning to prevent infection. Health education is indispensable to stop the habit. Another 3.8\% cleaned their EAC to mop out water after bath, overall, only $8.1 \%$ of the respondents agreed to replace the traditional tight 
cotton bud with a loose tip cotton bud despite adequate explanation that loose tip cotton bud is better because it absorbs more water and less traumatic. Reason for the choice of the tight cotton bud was due to its aesthetic appearance. In contrast, $24 \%$ of the subject in the study by Lee et al. [2] agreed to replace the conventional cotton bud with loose tip cotton bud.

It is important that in the interpretation of the findings in this study, some limitations present be considered. This was a hospital based study hence extending the findings to the community may be difficult. Also the sampling was mainly convenient and the subjects were relatively few. In spite of these, this report would appear as a call to action on self ear cleaning among the Nigerian population living in Sokoto metropolis.

\section{Conclusion}

The present study suggested that self ear cleaning habit is prevalent in Sokoto metropolis. The complications reported in this study suggested that future study should be community based on involving larger subjects.

\section{REFERENCES}

[1] A. O. Afolabi, A. M. Kodiya, A. Bakari and B. M. Ahmad, "Attitude of Self Ear Cleaning in Black Africans: Any Benefit?” East African Journal of Public Health, Vol. 6, No. 1, 2009, pp. 43-46. http://dx.doi.org/10.4314/eajph.v6i1.45743

[2] L. M. Lee, R. Govindaraju and S. K. Hon, "Cotton Bud and Ear Cleaning-A Loose Tip Cotton Bud?” Medical Journal Malaysia, Vol. 60, No. 1, 2005, pp. 85-88.

[3] T. Wright and P. Valentine, "The Anatomy and Embryology of the External and Middle Ear,” In: G. Michael,
Ed., Scott-Brown's Otorhinolaryngology, Head and Neck Surgery, 7th Edition, Vol. 3, Hodder Arnold, London, 2008, pp. 3107-3108. http://dx.doi.org/10.1201/b15118-248

[4] T. T. K. Junk and T. H. Jinn, "Diseases of the External Ear,” In: B. James, Ed., Ballenger's Otorhinolaryngology, Head and Neck Surgery, 16th Edition, BC Decker Inc., Hamilton, 2003, pp. 230-234.

[5] J. F. Guest, M. J. Greener, A. C. Robinson and A. F. Smith, "Impacted Cerumen: Composition, Production, Epidemiology and Management," Quarterly Journal of Medicine, Vol. 97, No. 8, 2004, pp. 477-488. http://dx.doi.org/10.1093/qjmed/hch082

[6] E. J. Propst, T. George, A. Janjua, A. James, P. Campisi and V. Forte, "Removal of Impacted Cerumen in Children Using an Aural Irrigation System,” International Journal of Pediatric Otorhinolaryngology, Vol. 76, No. 12, 2012, pp. 1840-1843.

http://dx.doi.org/10.1016/j.ijporl.2012.09.014

[7] P. S. Roland, T. L. Smith, S. R. Schwartz, R. M. Rosenfeld, B. Ballachanda, J. M. Earll, et al., "Clinical Practice Guideline: Cerumen Impaction,” American Academy of Otolaryngology-Head and Neck Surgery, Vol. 139, No. 3S2, 2008, pp. S1-S21.

[8] F. Jegoux, F. Legent and C. B. de Montreuil, "Chronic Cough and Ear Wax,” Lancet, Vol. 360, No. 9333, 2002, p. 618. www.thelancet.com http://dx.doi.org/10.1016/S0140-6736(02)09786-6

[9] M. Nussinovitch, A. Rimona, B. Volovitz, E. Ravehd, D. Prais and J. Amira, "Cotton-Tip Applicators as a Leading Cause of Otitis Externa,” International Journal of Pediatric Otorhinolaryngology, Vol. 68, No. 4, 2004, pp. 433435. http://dx.doi.org/10.1016/j.ijporl.2003.11.014

[10] P. Bhatia, “Aural and Nasal Foreign Bodies,” Nigerian Journal of Medical Practitioner, Vol. 14, No. 1-2, 1987, pp. 17-20. 